\author{
Ig. Iv. Chychura ${ }^{1}$, I.I. Turianytsia ${ }^{1}$, Iv.Iv. Chychura ${ }^{2}$
}

\title{
Temperature Dependence of The Optical Absorption Edge of Doped Gallium Arsenide
}

\author{
${ }^{I}$ National Universiry of Uzhhorod, Uzhhorod,Ukraine, igor.chechura@uzhnu.edu.ua \\ ${ }^{2}$ Institute of Electron Physics, Ukranian National Academy of Sciences, Uzhhorod, Ukraine, chechura89igor@gmail.com
}

\begin{abstract}
The temperature dependences of the optical absorption edges of $\mathrm{Zn}$ doped GaAs semiconductor crystals have been measured from 300 to $560 \mathrm{~K}$. The temperature dependence of the optical absorption in the Urbach edges is adequately reproduced by a Bose-Einstein model. Analysis of experimental results gave us the opportunity to offer an explicit function of two arguments (photon energy and temperature) for the absorption coefficient of doped crystals in the Urbach edge region.
\end{abstract}

Keywords: fiber-optic temperature sensors, Zn doped GaAs crystals, Optical transmission of doped GaAs crystals.

Received 14 March 2020; Accepted 15 June 2020.

\section{Introduction}

Analysis of experimental results gave us the opportunity to offer an explicit function of two arguments - photon energy and temperature, for the absorption coefficient of doped crystals in the Urbach region.

Basic materials of the $\mathrm{A}_{3} \mathrm{~B}_{5}$ group ( $\mathrm{GaAs}$ and $\mathrm{GaP}$ ) are the main complex semiconductor crystals for today. They are widely used in modern optoelectronics: basic elements of IR optics, television technology and fiber optic communications. After doping, these crystals are sufficiently resistant to radiation exposure, which enables their use in areas of high background radiation and even in extreme radiation conditions [1]. In addition to, the optical properties of such doped crystals are hardly affected by powerful electromagnetic fields [1]. All this indicates to the prospect of using crystals of the $\mathrm{A}_{3} \mathrm{~B}_{5}$ group as sensing elements of various fiber-optic sensors, which can be used in extreme conditions [3].

In the design process of modern fiber-optic information sensors the primary task is to optimize their basic optical parameters and characteristics. The initial data for such optimization are the spectra of optical transmission of crystals in the region of their absorption edge and theoretical functional relationships between there optical absorption values such as working wavelength of radiation and temperature. In addition, these characteristics change significantly with changes in the degree of crystals doping. Therefore, the study of all these problems is relevant for the development of modern and effective amplitude type fiber-optic sensors of physical quantities.

New developments in optical band-gap thermometry and rising of interest to thermal processing have created a need in more detailed information about temperature dependence of the optical absorption edges. As known, that in direct band-gap doped semiconductors, optical absorption in the area of the band gap increases exponentially with photon energy. This exponential rise in absorption, also known as "Urbach edge", is temperature dependent. It is a manifestation (representation) of the effect of structural and thermal disorder in electronic properties of such semiconductors.

Crystal lattices of binary type $\mathrm{A}^{\mathrm{III}} \mathrm{B}$ semiconductors have the structure of zinc blende (spatial symmetry group $T_{d}^{2}$ ) with two atoms per unit cell. In this case, there neighbors always are atoms of different elements. At $298 \mathrm{~K}$ a lattice constant of pure GaAs crystals is equal to $0.5693 \mathrm{~nm} \mathrm{[2],} \mathrm{and} \mathrm{the} \mathrm{energy} \mathrm{of} \mathrm{the} \mathrm{optical} \mathrm{absorption}$ edge is equal to $1.425 \mathrm{eB}$ [4]. As this semiconductor is 
direct gap semiconductor, then in the region of the edge of its own absorption, there is a spontaneous increase in absorption $\alpha$ optical radiation. Therefore, when the photon energy is greater than $1.5 \mathrm{eV}$, magnitude of $\alpha$ is already reaching values of $10^{4} \mathrm{sm}^{-1}$ [5].

In this article, it is reported optical transmission measurements of the Urbach edges of doped by $\mathrm{Zn} \mathrm{GaAs}$ samples from $300 \mathrm{~K}$ up to $560 \mathrm{~K}$. In the most cited temperature measurements of the band gap of GaAs, the temperature dependence of the band gap was inferred from isoabsorption measurements in the Urbach tail region. [6, 7]. But, the temperature dependence of the Urbach slope was not resolved [7]. This information is essential to obtain accurate mathematical function of many variables, which would sufficiently describe the magnitude of the optical absorption of the temperature sensitive elements, which were made from these crystals.

\section{Methods}

Single crystals of gallium arsenide (GaAs) have come to use in a wide range of optoelectronic applications, including the manufacture of semiconductor lasers and GaAs IC's. But it is difficult to obtain large GaAs single crystals with low dislocation density. The development of direct synthesis methods and the LEC (Liquid Encapsulated Czochralski) method made it possible. Now, high purity, GaAs single crystals produced by the LEC method are commercially available in the form of $\langle 100\rangle$ wafers having a diameter of two or three inches.

Today, however, more widely are used doped GaAs crystals. It is related to their advantages over pure crystals. In the measurements, reported in this work, we used zinc doped crystals, made by a Kyiv company "Monocrystal". The concentration of doping atoms was $6.8 \cdot 10^{+19}$.

For our optical studies, for more convenience, we used rectangular form plate. Crystal plates were cut out from solid material, which have been successively sanded and polished on diamond pastes of various consistencies. The final step was electro-polishing to a high roughness class. The result was $500 \mu \mathrm{m}$ thick plates with high surface quality on both sides (12-14 class) which were used as samples for these studies.

The absorption spectrum of samples and their temperature dependence were studied using a SF101 spectrophotometer according to the technique described in [8].

For these studies SF101 spectrophotometer has been modified. A heat-insulated box with spiral heater were installed in the measuring unit. This made it possible to significantly expand the temperature range of our research from 300 to $560 \mathrm{~K}$. Optical spectra were investigated using a single crystal plate, which was a sample of sensitive elements for fiber-optic temperature sensors.

\section{Results and discussion}

The absorption spectra for doped GaAs crystals are shown in Fig. 1. The resulting spectra provide workspace of transmission value changes for sensitive elements of temperature sensors at variations in the photon energy radiation and measured by temperature sensors. For comparison on Fig. 1, in the right corner, is shown the absorption spectrum of the undoped GaAs crystals at $383 \mathrm{~K}$ temperature [9]. Comparison of these graphs

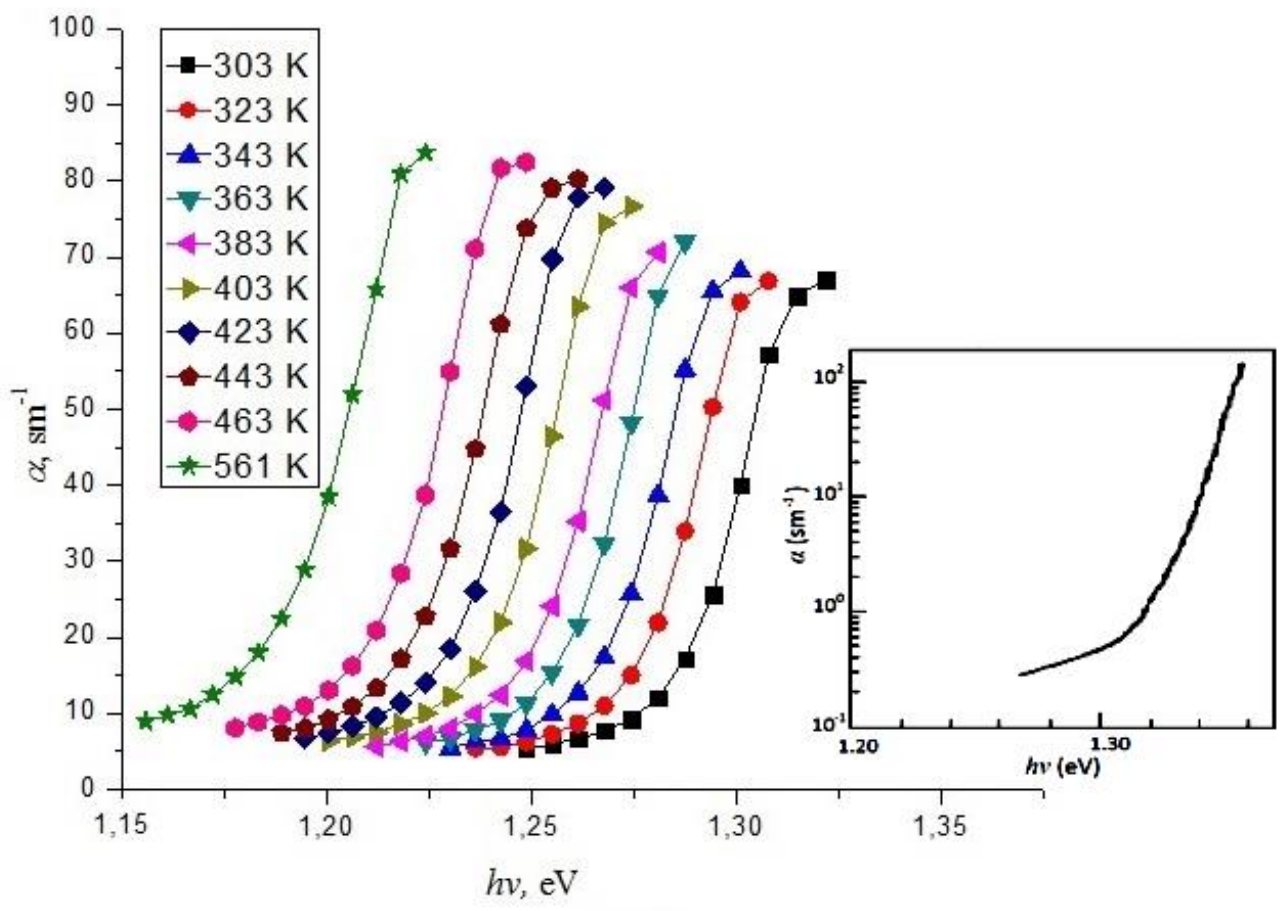

Fig. 1. Temperature dependence of absorption spectra $\alpha(h v)$ for doped GaAs crystals. (sample thickness $0.5 \mathrm{~mm})$. 
shows, that in doped crystals additional processes of photon absorption are realized, which form an additional "tail" in the area of small values of $\alpha$.

It was found that for doped GaAs crystals temperature dependence of the optical absorption spectrum $\alpha(\mathrm{h} v, \mathrm{~T})$, in the edge region, is well described by the expression [10]:

$$
\alpha(h v, T)=A(T)\left[h v-E_{\mathrm{g}}(T)\right]^{\frac{1}{2}}
$$

where: $A(T)$ - a certain temperature function, $E_{\mathrm{g}}(\mathrm{T})$ optical bandgap width as a function of temperature, $h v$ photon energy of optical radiation. Assuming, that this ratio will also be characteristically for doped crystals, we built a graph of $\alpha(\mathrm{h} v, \mathrm{~T})^{2}$ function from $\mathrm{h} v$. It is turned out, that it is poorly interpolated by a linear function. We believe that high doping in the crystals we use, make their structure strongly disordered. And for such structure expression (1) is not accurately describes the absorption edge, especially in the area of relatively small values of $\alpha$ up to $100 \mathrm{sm}^{-1}$ (see Fig. 1). Namely, this region of the edge is used as working area for different sensors made from these crystals. We believe that, in this case, the

specified region of absorption edge should be better represented as the absorption in the Urbach region by the Bose-Einstein model. In this case $\alpha(h v, T)$ can be described by [11]:

$$
\alpha(h v, T)=A(T) \exp \left(\frac{h v-E_{\mathrm{g}}(T)}{E_{0}(T)}\right),
$$

where $E_{0}(T)$ is the characteristic energy of the Urbach edge, $E_{\mathrm{g}}(T)$ is the extrapolated optical band-gap energy, and $A(T)$ is the optical absorption coefficient. It is clearly that all these parameters are temperature dependent. This mathematical function was used to analyze the absorption of GaAs crystals doped with other chemical elements by the authors of a number of works [12-14]. It is also assumed that the band gap in (2) is equal to the extrapolated optical gap. Although this may not give precisely the same values as other definitions of the band gap. form:

Ratio (2) is more convenient to use in converted

$$
\ln [\alpha(h v, T)]=\ln [A(T)]+\left(\frac{h v-E_{\mathrm{g}}(T)}{E_{0}(T)}\right)=\ln [A(T)]+B(T) \cdot h v-\frac{E_{\mathrm{g}}(T)}{E_{0}(T)}=A^{\prime \prime}(T)+B(T) \cdot h v
$$

In this case, we obtain for each temperature a linear dependence of the natural logarithm of the absorption coefficient from photon energy. Parameters of this linear dependence:

$$
\begin{aligned}
& A^{\prime \prime}(T)=\ln [A(T)]-E_{\mathrm{g}}(T) / E_{0}(T) \\
& \text { and } B(T)=1 / E_{0}(T)
\end{aligned}
$$

are functions of temperature.

Graphically, the results of such a logarithmic representation of the absorption edge in the range of values, up to $100 \mathrm{sm}^{-1}$ for $300 \mathrm{~K}$, are shown in fig. 2 .
From the graph can be seen the good interpolation accuracy of the experimental results of the absorption edge of the doped GaAs crystals by a linear function of the form (3). The maximum deviation of the process of interpolation of the edge at all temperatures does not exceed value $10 \%$. Values of the obtained parameters of interpolation of the absorption edge at different temperatures are shown in table 1.

The temperature dependences of the parameters $E_{0}$, $E_{\mathrm{g}}$ and $A$ (Urbach region) edge are shown in Fig. 2-4. The characteristic energy $E_{0}$ shows some growth with

Table 1

Parameters of interpolation of the absorption edge of doped GaAs crystals by linear function (3) and defined from them parameters of Urbach region (2)

\begin{tabular}{|c|c|c|c|c|c|c|}
\hline$T, \mathrm{~K}$ & $A^{\prime \prime}(T)$, a.u. & $B(T), \mathrm{eV}^{-1}$ & $E_{0}(T), \mathrm{eV}$ & $E_{\mathrm{g}}(T), \mathrm{eV}$ & $E_{\mathrm{g}}(T) / E_{0}$, a.u. & $A(T), \mathrm{cm}^{-1}$ \\
\hline 303.00 & -73.17 & 58.90 & 0.0170 & 1.275 & 75.00 & 6.23 \\
\hline 323.00 & -71.96 & 58.57 & 0.0171 & 1.265 & 73.98 & 7.52 \\
\hline 343.00 & -70.32 & 57.39 & 0.0174 & 1.26 & 72.41 & 8.11 \\
\hline 363.00 & -69.43 & 57.08 & 0.0175 & 1.255 & 71.71 & 9.83 \\
\hline 383.00 & -67.97 & 56.46 & 0.0177 & 1.245 & 70.34 & 10.73 \\
\hline 403.00 & -66.21 & 55.68 & 0.0180 & 1.235 & 68.61 & 11.09 \\
\hline 423.00 & -64.10 & 54.39 & 0.0184 & 1.225 & 66.58 & 11.94 \\
\hline 443.00 & -62.06 & 52.93 & 0.0189 & 1.22 & 64.55 & 12.01 \\
\hline 463.00 & -59.46 & 51.18 & 0.0195 & 1.21 & 62.05 & 13.35 \\
\hline 563.00 & -51.95 & 46.33 & 0.0216 & 1.18 & 54.63 & 14.54 \\
\hline
\end{tabular}


temperature increasing. Similar temperature behavior was observed by the authors of the paper [9] for undoped GaAs crystals and authors of the paper [15] for crystals doped with silicon atoms with concentration of $2 \cdot 10^{18}$ atoms $/ \mathrm{sm}^{3}$. At this time, the value of this parameter for zinc-doped crystals is about three times greater, in contrast to undoped, and only for $3 \mathrm{meV}$ higher than in nitrogen-doped crystals.

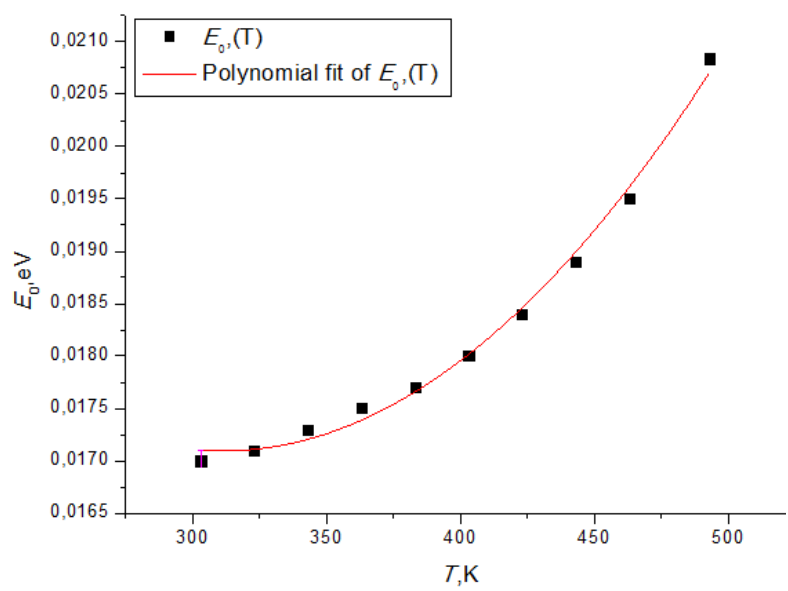

Fig. 2. Temperature dependence of $E_{0}$ for doped GaAs crystal.

Temperature dependence of $E_{0}(T)$ in the range from 300 to $500 \mathrm{~K}$ can by well described by a second-order polynomial, as in work [9] for undoped crystals. However, the bending of the polynomial graphs for these two cases is opposite. At temperatures higher than $500 \mathrm{~K}$, in our studies, and in work [13] there is some deviation from the quadratic dependence. At the same time, for nitrogen-doped crystals scatter of experimental points did not allow the authors [15] accurately evaluate the mathematical form of dependence $E_{0}(T)$ and they considered it linear. According to our experimental data, we presented this mathematical function in the form:

$$
E_{0}(T)=e_{0}+e_{\mathrm{a}} \cdot T+e_{\mathrm{b}} \cdot T^{2}
$$

where the coefficients of the polynomials $e_{0}, e_{\mathrm{a}}$ and $e_{\mathrm{b}}$ are shown in table 2 in the form of certain value.

Investigated size of the optical bandgap of the zinc doped GaAs crystals is $0.2 \mathrm{eV}$ smaller, compared to undoped. With temperature increasing value of $E_{\mathrm{g}}$ naturally decreases (Fig. 4). In this case, the average coefficient of temperature changes is approximately equal to $-3 \cdot 10^{-4} \mathrm{eV} / \mathrm{K}$. For undoped crystals according to the work [9] such temperature changes are characterized by twice bigger temperature coefficients. Note that GaAs crystals doped with nitrogen to a concentration of 3.75 at. $\%$ leads to twice bigger changes in optical bandgap (decreases at $300 \mathrm{~K}$ from $1.42 \mathrm{eV}$ to $1.03 \mathrm{eV}$ ) [10], however, the temperature coefficient for all doped like these crystals is much smaller and does not exceed $-2 \cdot 10^{-4} \mathrm{eV} / \mathrm{K}$. In another place, silicon doping to concentration $2 \cdot 10^{18}$ atoms $/ \mathrm{sm}^{-3}$ on the contrary increases $E_{\mathrm{g}}$ crystals approximately for 0.2 [15] preserving the coefficient of temperature changes at about $-6 \cdot 10^{-4}$, similar to undoped GaAs crystals.
According to the graph (Fig. 3), the temperature dependence of $E_{\mathrm{g}}$ is described by a second-degree polynomial which gives representation close to a linear. The only exception is a point about $600 \mathrm{~K}$ that "falls out" from the specified regularity. The same function is using to presented bandgap of nitrogen doped GaAs crystals [9]. At the same time, the linear character of the $E_{\mathrm{g}}(T)$ function was established for undoped and silicon doped crystals [9, 15]. Considering the above facts, we presented $E_{\mathrm{g}}(T)$ via second degree polynomial (exclusion end point, around $600 \mathrm{~K}$ ) whose explicit form is recorded in table.2, as for the function $E_{0}(T)$. Representation of $E_{\mathrm{g}}$ (T) via linear function leads to much larger absolute errors.

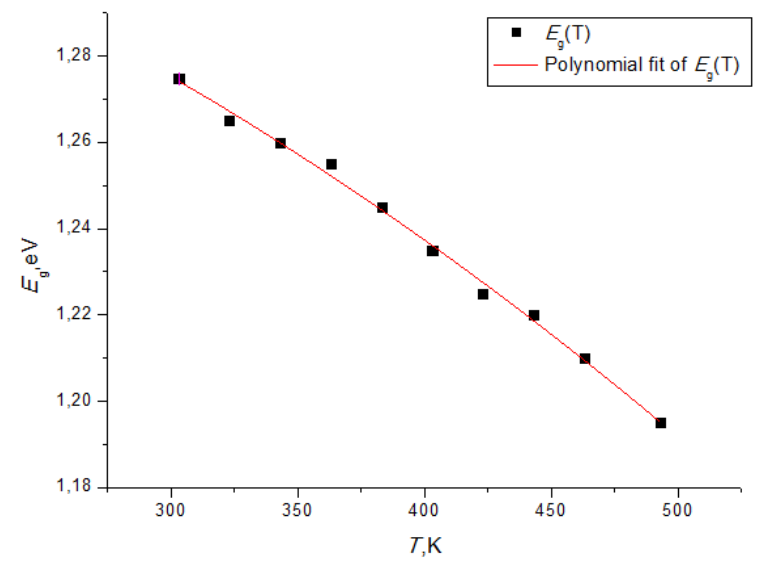

Fig. 3. Temperature dependence of $E_{g}$ for doped GaAs crystal.

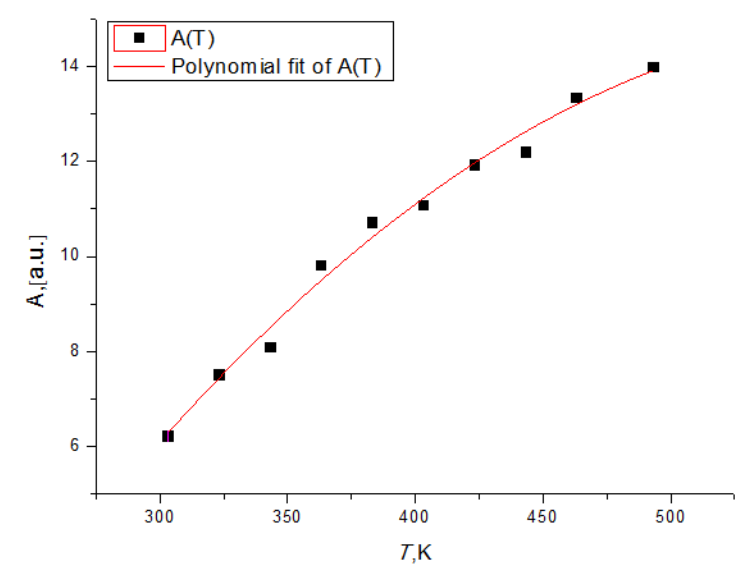

Fig. 4. Temperature dependence of A parameter for interpolation of the absorption edge of doped GaAs crystals.

According to the ratio (2), $A$ (T) parameter determines the value of the optical absorption coefficient at $\mathrm{T}$ temperature for photon energy $h v=E_{\mathrm{g}}(T)$. Its behavior with temperature increasing is presented on Fig. 4. Accordingly to the shape of $E_{\mathrm{g}}$ on $T$ function on Fig. 3 here is again sine evident of second-degree polynomial behavior. As in the previous cases, the point at $600 \mathrm{~K}$ does not fall into this pattern, which we exclude from further analysis. An explicit view of the obtained by us polynomial is given in table 2 . 
Table 2 Parameters of the Urbach edge using polynomials of the second degree, and errors of their representation.

\begin{tabular}{|c|c|}
\hline Parameter & Error \\
\hline$E_{0}(T)=1,1 \cdot 10^{-7} \cdot T^{2}-6,8 \cdot 10^{-5} \cdot T+0,027$ & $10 \%$ \\
\hline$E_{\mathrm{g}}(T)=-3,9 \cdot 10^{-7} \cdot T^{2}-1,1 \cdot 10^{-4} \cdot T+0,027$ & $8 \%$ \\
\hline$A(T)=-1,0 \cdot 10^{-4} \cdot T^{2}+0,12 \cdot T-21,3$ & $15 \%$ \\
\hline
\end{tabular}

Using all the results obtained in processing of experimental data, a clear mathematical relation can be written, which sets the optical absorption coefficient for sensitive elements made of zinc doped GaAs crystals for fiber optic temperature sensors: (three options replace by their polynomials) in formula (2).

The resulting ratio allows to conduct theoretical analysis enough accurately. And also perform modeling and optimization of operational parameters for optical temperature sensors using information about investigated crystals.

\section{Conclusions}

The behavior of the optical absorption edge of zincdoped GaAs crystals at temperature changes from 300 to
$560 \mathrm{~K}$ was investigated. Near-parallel shift of the absorption edge into the region of lower photon energies of optical radiation with increasing temperature was obtained. It is shown that in the absorption region up to $100 \mathrm{~cm}^{-1}$, the spectrum has the character of the Urbach edge. The temperature shift of the edge may be explained by the increase in the dynamic structural disorder of the lattice of doped crystals with temperature increasing within the Bose-Einstein model. The temperature dependences of the Urbach edge parameters are determined. It is shown that these dependencies are better described by polynomials of the second degree than by linear functions. Offered a correct view of the absorption coefficient in Urbach edge as a function of two arguments (photon energy and temperature) based on our results. It was noted the importance of establishing of such function for parameters modeling and optimization of GaAs crystals optical sensors.

Chychura Ig. Iv. - senior officer;

Turianytsia I.I. - Dean of the Faculty of Engineering and Technology;

Chychura Iv.Iv. - Provider engineer of department functional electronics.

[1] John D. Cressler, H. Alan, Technology \& Engineering (Mantooth Extreme Environment Electronics CRC Press, 2017).

[2] Hamad Jappor, European Journal of Scientific Research 59, 264 (2011).

[3] Igor Chychura, Fiber-Optic Temperature Sensors with Chalcogenide Glass and Crystalline Sensing Element (2019) (https://doi.org/10.5772/intechopen.89207).

[4] M. Beaudoin, \& A. DeVries, \& S.R. Johnson, \& H. Laman, \& Tom Tiedje, Applied Physics Letters 70,3540 (1997) (https://doi.org/10.1063/1.119226).

[5] J. Akinlami, \& A. Ashamu, Journal of Semiconductors 34, 032002 (2013) (https://doi.org/10.1088/16744926/34/3/032002).

[6] C.D. Thurmond, J. Electrochem. Soc. 122, 1133 (1975) (https://doi.org/10.1149/1.2134410).

[7] M.B. Panish and H.C. Casey, J. Appl. Phys. 40, 163 (1969) (https://doi.org/10.1063/1.1657024).

[8] Tauc, Progr. Semiconductors 9, 89 (1965).

[9] M. Beaudoin, Appl. Phys. Lett. 70, 3540 (1997) (https://doi.org/10.1063/1.119226).

[10] Y. Zhao, M. Rong, I. Liao, IEEE Sensors Journal 3(4), 400 (2003).

[11] G.D. Cody, Semiconductors and Semimetals, edited by J. I. Pankove (Academic, 1984).

[12] Katsuhiro Uesugi, Appl. Phys. Lett. 76, 1285 (2000) (https://doi.org/10.1063/1.126010).

[13] Yoshida Junichi et al, Jpn. J. Appl. Phys. 42, 371 (2003) (https://doi.org/10.1143/JJAP.42.371).

[14] Ikuo Suemune, \& K. Uesugi, Appl. Phys. Lett. 77, 3021 (2000) (https://doi.org/10.1063/1.1322633).

[15] S.R. Johnson and T. Tiedje, Journal of Applied Physics 78, 5609 (1995) (https://doi.org/10.1063/1.359683). 


\title{
Іг. Ів. Чичура ${ }^{1}$, I.I. Туряниця ${ }^{1}$, Ів.Ів. Чичура ${ }^{2}$ \\ Температурна залежність краю поглинання легованих кристалів арсеніду галію
}

\author{
${ }^{1}$ Ужгородський наџіональний університет, Ужгород, Украӥна, igor.chechura@uzhnи.edu.иа \\ ${ }^{2}$ Інститут електронної фізики, Національна академія наук України, \\ Ужсгород, Україна, chechura89igor@gmail.com
}

Температурна залежність фундаментального краю поглинання легованих цинком кристалів GaAs досліджувалася у діапазоні від 300 до 560 К. Температурна залежність краю фундаментального поглинання може бути представлена моделлю Бозе-Ейнштейна. Аналіз експериментальних даних дав нам можливість запропонувати функцію двох змінних (енергії фотонів та температури) для коефіцієнта поглинання у легованих кристалах у зоні краю поглинання.

Ключові слова: Волоконно-оптичний датчик температури , Леговані цинком кристали GaAs, Оптичне пропускання легованих кристалів GaAs. 